\title{
La Puerta de Córdoba como espacio museográfico y contenido museológico
}

\author{
Reyes Ojeda Calvo \\ Antonio Pérez Paz \\ Arqueólogos
}

Una vez concluida, en su mayor parte, la investigación centrada en la Puerta de Córdoba de Carmona y su entorno, desentrañados su estructura y sentido, concluida la fase de restauración del inmueble, llega el momento de pasar al capítulo siguiente, el de su presentación en sociedad '. Es preciso ahora transferir a la comunidad el edificio en toda su significación, entregárselo preparado otra vez para su uso, remozado, para que lo comprenda, lo aprecie, lo cuide.

En estas pocas páginas procuraremos esbozar una propuesta interpretativa en la que se dibujen mínimamente los elementos principales del proceso: el qué queremos transmitir, a quién nos vamos a dirigir, dónde y de qué manera pretendemos hacerlo. No se trata, entonces, de desarrollar ahora todo un proyecto interpretativo, ni de explicar la temática completa, pero sí de sugerir por qué caminos podría discurrir la comunicación.

\section{Planteamientos de la comunicación}

Lo primero que nos parece evidente en estos momentos iniciales de la interpretación es la existencia de un binomio invariable, un par que es el alfa y la omega de todo el proceso: el bien patrimonial y el sujeto receptor del mensaje. No vamos a detenernos a mencionar las reglas básicas que hemos aprendido o los lugares comunes más o menos aceptados en los foros especializados, pero será inevitable que alguno de ellos asome de vez en cuando. Y la primera obviedad a decir es que hay todavía un cierto camino a recorrer entre el momento actual, con el inmueble ya estudiado y restaurado, y el instante en que lo podremos considerar apto para su percepción. No es que ahora sea imposible visitar la Puerta sino que aún no ha sido elaborado el mensaje a transmitir, no hemos transformado la ingente base de datos de que disponemos en los contenidos que van a configurar la experiencia que el visitante vive cuando contacta con el bien patrimonial. Queda, en suma, desarrollar la interpretación.

La intención que subyace en la acción de comunicar es la de conectar con el público receptor del mensaje, pero no se pretende tanto hacérselo llegar como, sobre todo, ponerlo a su alcance para que él mismo lo tome y lo integre en la medida que le apetezca o necesite. Se trata, pues, de trabajar la interpretación, la comunicación, para que se convierta, como decimos, en una experiencia personal por parte del usuario, del consumidor de "ocio cultural", del habitante local.

Pensar en este público no es entonces, como puede suponerse, el menor de los problemas de un plan de interpretación. Y menos en el caso que contemplamos: hay que comunicar lo esencial de un elemento patrimonial que no es de uso minoritario, sino todo lo contrario, que no es un raro teorema que pueda explicarse en una vitrina, ni una valiosa escultura protegida por la oscuridad hasta que el espectador deposita la moneda en el mecanismo de rigor. La Puerta de Córdoba es uno de los espacios más transitados de la ciudad, paso obligado de extramuros a intramuros en este extremo del solar urbano, portada de Carmona hacia el Levante, fachada de viviendas, muro de carga, tapia, calle. Y es, sobre todo esto, identidad local. No es nada fácil hablar de este bien inmueble a todo su público potencial.

Puede hacerse acometiendo un plan de interpretación adaptado a ese binomio a que hacíamos referencia, hecho a medida, ceñido al espacio y a los medios disponibles. Un plan que permita el acercamiento tanto del especialista (que, por serlo, dispone, además, de otros cauces para acceder a la información), como del turista (interesado a menudo en 
En la Puerta, se nos brinda la oportunidad de adaptar el ámbito expositivo como espacio escénico. El Edificio, gracias a su corporeidad, a su presencia, ahora remozada, en el emplazamiento original, como elemento destacado en la ciudad y en el paisaje anejo, es capaz de "escenificar" buena parte de los valores museológicos que queremos transmitir.

ofertas que combinan cultura y ocio), del público escolar y, sobre todo, del habitante local. En este caso no se trata de convertir algo en producto patrimonial porque la Puerta ya es monumento y forma parte de la memoria colectiva de la Ciudad, sino de enriquecer las visiones de este elemento y el modo de acceder a él.

Y para qué interesa llevar a cabo este plan de interpretación. Por lo pronto, como decíamos al principio, es derecho de la comunidad acceder a su patrimonio para asumirlo y disfrutarlo pero, además, el patrimonio cultural necesita de la identificación y apropiación por parte de la comunidad para, una vez restaurado, revivido, conservar la buena salud. A lo largo de estas páginas aflorará de vez en cuando el concepto "conservación" referido a diversos ámbitos, pero ahora queremos emplearlo para subrayar algo que nos parece evidente: gracias a su función conservativa, convertimos la interpretación en un eficaz instrumento para la gestión patrimonial.

Cómo podemos estar seguros de que este enorme esfuerzo comunicativo va a surtir los efectos deseados, cómo garantizamos los resultados que nos interesan. La respuesta no puede ser otra: elaborando un producto sugerente. Ya sabemos que casi todo lo que causa placer y felicidad perdura, así que esa experiencia que queremos provocar tiene que ser creada con estas miras, ha de recordarse luego como algo feliz y placentero. No se trata, por supuesto, de "aligerar" los contenidos ni de tergiversar la información, sino de que ésta llegue al receptor como un descubrimiento personal, como una emoción, un estímulo que le lleve a reflexionar, que le inspire ciertos valores, que le sugiera lecturas de la realidad no imaginadas hasta ese momento.

\section{Los espacios museográficos}

Por lo que respecta a los espacios expositivos, nos parece de enorme interés presentar el discurso en dos puntos complementarios que permitan conciliar sendos modos de transmitir no necesariamente contrapuestos. Desde luego, la Puerta de Córdoba y su entorno son enclaves privilegiados para la exhibición del mensaje, pero no ha de menospreciarse el papel que desempeñaría una exposición de parte de los contenidos que nos interesan en un lugar distinto de la Puerta. Dónde: un centro de visitantes, de información, un museo.

No es aconsejable ni factible, en una ciudad como Carmona, que tiene ya diseñada la oferta cultural, crear de la nada un espacio expositivo donde puedan ser solventadas las carencias que como tal y para la transmisión de determinados contenidos, presenta la Puerta. Basta, en este caso, pensar en lo que sería más conveniente para la consecución de los propósitos del plan de interpretación. Así que, sin pretender asumir competencias que no nos son propias, ni injerir en modo alguno en las labores que con tanta solvencia desarrollan sus responsables, no podemos menos que sugerir la idoneidad del Museo de la Ciudad para albergar uno de los polos expositivos principales de la Puerta de Córdoba.

Si esto fuera posible, abarcaríamos un segmento de la ciudad muy próximo a lo que fue cardo romano, uno de los ejes vertebradores del espacio urbano

Estado actual del flanco meridional de la portada interior de la Puerta romana (casa n ${ }^{\circ} 32$ en calle D. Quintanilla).

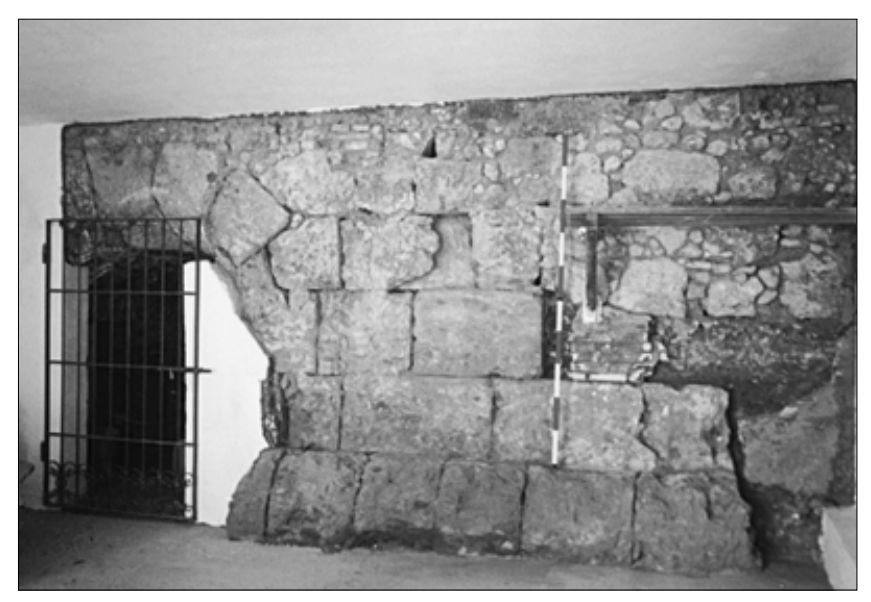



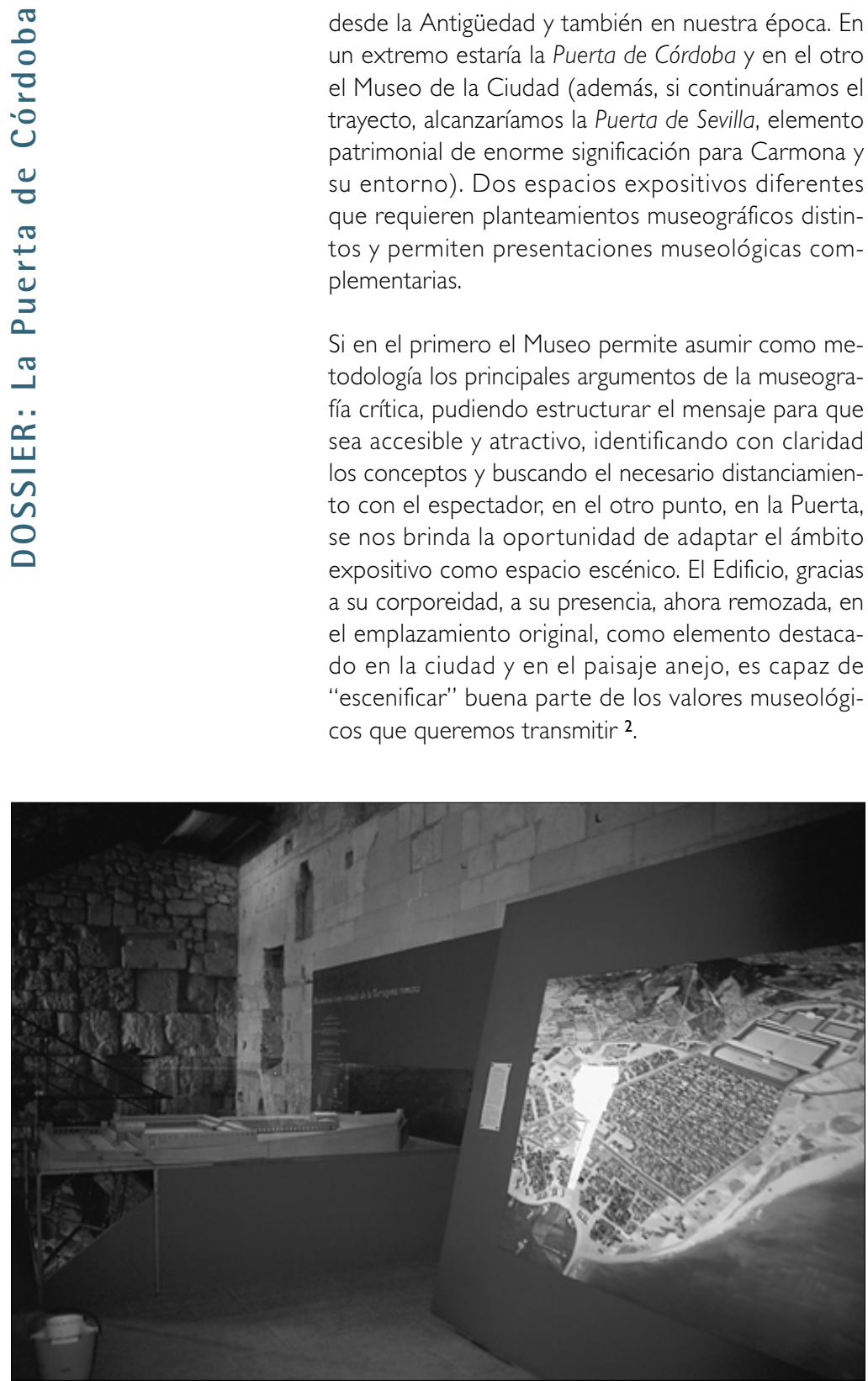

Interior de la llamada Torre del Pretorio (Tarragona) con espacio habilitado para desarrollar parte del discurso museológico desde la Antigüedad y también en nuestra época. En un extremo estaría la Puerta de Córdoba y en el otro el Museo de la Ciudad (además, si continuáramos el trayecto, alcanzaríamos la Puerta de Sevilla, elemento patrimonial de enorme significación para Carmona y su entorno). Dos espacios expositivos diferentes que requieren planteamientos museográficos distintos y permiten presentaciones museológicas complementarias.

Si en el primero el Museo permite asumir como metodología los principales argumentos de la museografía crítica, pudiendo estructurar el mensaje para que sea accesible y atractivo, identificando con claridad los conceptos y buscando el necesario distanciamiento con el espectador, en el otro punto, en la Puerta, se nos brinda la oportunidad de adaptar el ámbito expositivo como espacio escénico. El Edificio, gracias a su corporeidad, a su presencia, ahora remozada, en el emplazamiento original, como elemento destacado en la ciudad y en el paisaje anejo, es capaz de "escenificar" buena parte de los valores museológicos que queremos transmitir 2

\section{El Museo de la Ciudad alberga los episodios funda-} mentales que han ido definiendo el carácter de Carmona, su personalidad actual. Es aquí donde cabe contextualizar el discurso museológico de la Puerta. Ningún sitio mejor para organizar el mensaje, para estructurar y sistematizar los contenidos. Y es también el Museo el lugar idóneo para explicar al visitante ciertos temas como los referidos al amurallamiento de Carmona, a su urbanismo, a sus canteras, pero, sobre todo, es el mejor espacio para ilustrar las estrechas relaciones habidas entre la Puerta y la Ciudad, que lo son tanto que la una alberga a la otra en su propia definición. Este punto de vista sería más difícil de transmitir si tuviéramos como único espacio expositivo el propio Edificio.

En las salas del Museo puede establecerse una arquitectura museográfica, con la ubicación predeterminada de cada uno de los materiales diseñados para favorecer la comunicación, con el trazado de diversos circuitos de circulación para su libre seguimiento (somos conscientes de que no es posible, ni aconsejable siquiera, forzar la lectura secuencial de los elementos expositivos); es decir, que se puede proyectar, con menores limitaciones que en la propia Puerta, la representación del discurso museológico y, de este modo, procurar llevar a cabo esa museografía crítica a la que aludíamos más arriba (en el ámbito expositivo de la Puerta, en cambio, hemos de adaptar la museografía a la configuración formal del propio edificio).

La disposición de medios interpretativos en este espacio depende, desde luego, de las necesidades comunicativas del proyecto pero, también, de la filosofía propia del Museo y de sus directrices museográficas. No obstante, cabe decir que en este ámbito expositivo de la Puerta debería primar una estructuración del mensaje, una intención de transmitir con claridad contenidos concisos que faciliten la comprensión y que atraigan lo suficiente como para motivar al visitante a pasear luego hasta el propio Edificio. Para conseguir estos propósitos puede emplearse unos materiales que irían desde el práctico folleto temático hasta una exhibición tridimensional que ilustre, por ejemplo, la articulación urbanística del área dominada por la Puerta. El visitante debe poder identificar de una manera sencilla cada uno de los bloques expositivos con la temática a la que alude; podrá, así, circular libremente, sin temor a perderse nada, para desentrañar aquellos aspectos que le resulten más interesantes. De este modo, se le ayuda a organizar la información y se le estimula para que continúe con la experiencia.

En el otro espacio museográfico tiene lugar la exposición de la Puerta a cargo de ella misma. Si bien en el Museo se ha procurado transmitir las claves básicas para acceder al edificio exhibido, aquí se persigue provocar una vivencia. Es esto lo que se pretende suscitar, una experiencia compleja y única para cada individuo. En la visita a la Puerta el hombre de hoy penetra en una atmósfera milenaria y actual a un tiempo, en un organismo que vive desde principios de nuestra Era y ha sido testigo tanto de sucesos reflejados en la historiografía como de episodios anónimos.

Aquí es más sencillo acceder al conocimiento del Edificio, de su materialidad y su volumetría. El visitante aprecia, de manera intuitiva, la entidad del Proyecto original y lo hace colocándose al pie del podio de la Puerta romana, accediendo a la caja de escalera, ascendiendo a la planta alta y contemplando allí, como en su día hicieron los defensores, los muros y las torres.

Cuando sube al ático o asoma el cuerpo entre los merlones, se encuentra con el paisaje, se identifica con el edificio, se siente parte de la topografía, dominando el espacio, la Vega, la Vía. La comunión con la Puerta y su entorno no tiene más límite que la prisa. 
Aquí, el visitante puede comprender, casi corpóreamente, el significado de la Puerta en la ciudad, como fortificación y como monumento, su papel como interrupción y como nexo en el alcor, su labor en la continuidad del paisaje al tiempo que ejerce de frontera entre el espacio de la ciudad y el del campo. Muralla y vano. Cierre y acceso. Defensa y emblema de Carmona.

Para ayudar al espectador a comprender el Edificio que está recorriendo, con partes y elementos que evidencian diferentes épocas, es dispuesta una selección de materiales comunicativos. Prima en ellos la voluntad de no eclipsar a la propia Puerta, de no consumir el oxígeno que se necesita para disfrutar de la visita a un espacio que es, de por sí, reducido, con escasas posibilidades para la libre circulación (el edificio ha llegado hasta nosotros con viviendas adosadas a sus muros, ocultos puntualmente debido a colmataciones de depósitos que han elevado los niveles de suelo). Breves textos en una cartelería bien compuesta y un buen aparato gráfico, tridimensional siempre que es posible, son diseminados por la estructura para que los use quien desee encontrarse con ellos. No hemos de olvidar que en este espacio museográfico van a destacar los contenidos esenciales, no se va a abundar en lo transmitido ya en el Museo de la Ciudad y, además, se pretende que prime la posibilidad de suscitar en el espectador sensaciones, emociones, quizá evocaciones de un mundo, de ambientes, que cree conocer gracias a la interpretación de la temática. Esta búsqueda de una experiencia estética, casi al modo renacentista, en la que el descubrimiento está ligado al placer de los sentidos, no debe, sin embargo, desvirtuar la función didáctica que también subyace en la comunicación.

Este material ha de estar ordenado jerárquicamente y para esto hay que comenzar disponiendo ante el visitante un elemento organizador; éste, que pudiera ser aquí un audiovisual automático (que, junto al montaje de una página web, permite "exportar" la interpretación a otros lugares), puede ilustrar, entre otros temas, la evolución seguida por el bien inmueble a lo largo de los siglos así como el propio proceso de recuperación. Aspectos como la articulación espacial o las hipótesis de restitución, encuentran un medio adecuado en los modelos tridimensionales en movimiento 3

Ir unos pasos más allá, atravesar la Puerta para convertir el paisaje periurbano en un tercer espacio expositivo, es una oportunidad que no debe ser desperdiciada. No vamos a conformarnos con asomar al espectador a la cumbre del Edificio para que desde allí, dominando la Vega del Corbones, se haga una idea más o menos fiel de la topografía donde se implanta. Trascenderemos el ámbito reducido, finito de la Puerta, de la Ciudad, y nos trasladaremos al espacio de más allá. El diseño de un par de recorridos señalizados y explicados in situ puede permitir al visitante conocer los puentes, la vía, la cantera, los vestigios de las necrópolis, además de poder contemplar el inmueble desde una cota inferior, lo que

facilitará la comparación de su aspecto actual con el que tuvo en otras épocas. Si desde arriba, desde el ático del edificio, el espectador puede apreciar el papel de la Puerta en la defensa de la Ciudad, es desde abajo y en el exterior como percibe su carácter emblemático.

Es especialmente interesante ceñir la vastedad de este espacio expositivo gracias a unos itinerarios bien definidos, ya que, de otro modo, la dispersión de los usuarios restará eficacia a la intención museológica prefijada. Aquí, como resulta evidente, es el trazado del recorrido el elemento organizador del mensaje. Su diseño recrea la acción de aproximarse a la Puerta y de pasar a la ciudad atravesando su vano. Al hacerlo estamos completando un ritual que nos asemeja a los hombres que han repetido el mismo gesto a lo largo de dos milenios, estamos trasponiendo límites temporales, empezando a vislumbrar lo que es verdaderamente esencial en todo esto.

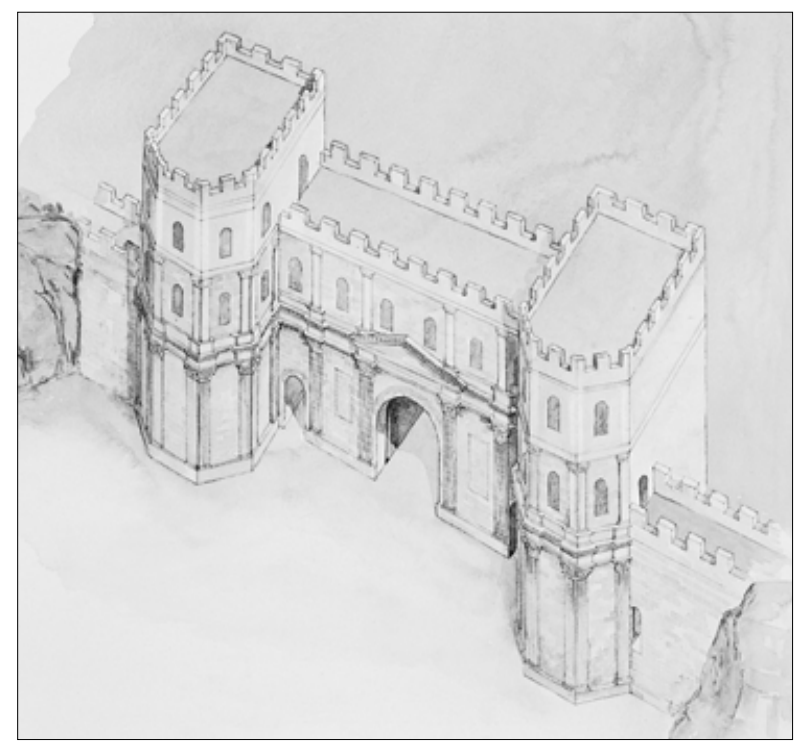

\section{Temática de la interpretación}

Como decíamos al iniciar estas páginas, no viene al caso detallar ahora todos los contenidos que podrían conformar el discurso, pero sí conviene hacer una breve presentación de los que podrían llegar a ser sus bloques principales. De este modo, avanzamos estos conjuntos temáticos sin establecer ahora la jerarquización que será necesaria más tarde, en el momento de elaborar el plan de interpretación. No es ésta, desde luego, toda la información que puede ofrecerse pero sí casi toda la principal. Tampoco pretendemos esbozar lo que pudiera ser el proyecto museológico, sino, tan sólo, plantear en este foro de profesionales del Patrimonio algunos de los elementos que pueden ser considerados para su reflexión. El establecimiento de criterios interpretativos conllevará la estructuración de los contenidos pero, también, su purga y la eliminación de muchos aspectos; en otras palabras, alcanzar los propósitos de la comunicación es siempre más importante que ofrecer a toda costa el saber enciclopédico acumulado
Primer ensayo de restitución hipotética de la fachada exterior (dibujo de F. Salado, 1996), utilizado en el apartado gráfico referente a Carmo del Proyecto Ruta Bética Romana 
acerca del elemento a interpretar. Si, para conseguir los objetivos, hay que sacrificar algo, que sea la cantidad de información, nunca su calidad.

\section{Nacimiento del Edificio. La Puerta en la Ciudad antigua}

\section{Temática principal}

- El tránsito entre el espacio urbano y el periurbano (contextualización simbólica)

- La Puerta como fortificación (funcionalidad / contextualización espacial)

- El programa monumental de época romana (funcionalidad / contextualización socio-política)

\section{Temática accesoria}

- Roma y la provincia Bética. Carmona en el siglo I d.C.

- Los Alcores

- La Vía Augusta

- Ciudad y territorio. El paisaje en la Antigüedad

- La Puerta de Sevilla de Carmona

Consideramos que este primer bloque temático puede tratarse con independencia de la evolución general que se contempla en el segundo por una razón fundamental: conviene trasladar al hombre de hoy la mentalidad del que concibió y creó la Puerta. Aquí se presenta a la ciudad como un microcosmos hecho por el hombre a la medida del hombre; en ella se refugia de las incertidumbres del mundo silvestre, en ella construye una existencia segura donde puede ceñir el medio natural a unos límites dibujados por él mismo. El hombre ciudadano del mundo antiguo, más próximo a lo rural, necesita separar el campo de la ciudad abarcándola entera con un cinturón murado. Pertenece, además, a una sociedad identificada hasta cierto punto con el orden celeste, con el ámbito ordenado, jerarquizado de lo divino, y procura que la gracia de los dioses bañe y proteja el solar urbano, donde duerme. En el cuerpo de las murallas materializa este amparo y hasta su perímetro extiende la influencia de los templos. Extramuros se encuentra el territorio que los hombres controlan gracias no sólo a la técnica, a la ingeniería, sino también a la extensa red de vías que comunica los espacios colonizados. Los muros defensivos son, pues, la piel de la ciudad y su coraza, la linde que sólo debe traspasarse de modo pacífico. Y este paso, esta transformación casi imperceptible, se opera a través de la puerta ciudadana, única interrupción posible de la muralla y vehículo para trasladarse de un mundo al otro.

Carmona es ciudad pero también fortaleza. No es casual que desempeñara un papel preponderante en la resistencia a Roma primero y, más tarde, en los conflictos de la época de César, quien dijo que era "con mucho, la ciudad más fuerte de toda la provincia [Bética]" 4. El carácter de defensa urbana que asume la puerta como elemento capital en la muraIla queda resaltado y fortalecido en la de Córdoba de Carmona gracias a su ubicación topográfica. He- mos de detenernos aquí para contextualizar geográficamente el bien inmueble y la ciudad a la que pertenece, para tratar Los Alcores, verdadero acantilado que se yergue sobre la Vega. La fertilidad de Los Alcores, sus acuíferos, su antiquísimo poblamiento, se ven reflejados en la feracidad de La Vega, vasto granero del que se nutre Carmona. Hasta ésta llega el alimento a través de un extenso sistema circulatorio del que cabe destacar su arteria principal, la Vía Augusta, que se funde con la ciudad precisamente bajo el arco de la Puerta de Córdoba.

En el extremo opuesto del cardo máximo se levanta el imponente volumen de la otra puerta urbana que conserva Carmona, la de Sevilla. Ambos accesos y la vía que los une constituyen un armazón perfecto para construir el tema del urbanismo carmonense en la Antigüedad.

La concepción monumental de la Puerta la convierte en destacado exponente de la propaganda imperial y pieza fundamental en la dignificación de la urbe. Carmona es, en esta época, referente obligado para otras poblaciones de la Provincia Bética, imagen de la esencia de Roma y modelo en su entorno. La Puerta, concebida como arco honorífico inserto en la muralla y dando paso a la Via Augusta, fabricada en sillería bien aparejada, revestida con relucientes estucos y ceñida por dos altas torres, es la imagen de Carmona que percibe el viajero que proviene de Écija. Es en esta imagen donde acaba el campo, donde el paisaje se transforma.

En este tema cabe dedicar un capítulo a describir la compleja relación que se establece entre la ciudad y su territorio, así como a tratar la concepción del paisaje en la Antigüedad, el modo en que el hombre lo transforma con la fundación de las ciudades, con la parcelación para el cultivo, con las obras de ingeniería. En Los Alcores disponemos de las canteras como elemento museológico que sintetiza a la perfección estos conceptos y, en Carmona, una visión del imponente espacio escultórico de La Batida basta para concebir el proceso de modelado a que el hombre ha sometido el perfil natural del alcor.

\section{Tiempo y Edificio. Evolución histórica y material de la Puerta de Córdoba.}

\section{Temática principal}

- Valores arquitectónicos y ambientales de la Puerta. (composición material y espacial)

- Transformación (evolución histórica y funcional)

- La Puerta para el hombre de hoy (conservación y uso)

\section{Temática accesoria}

- José de Echamorro

- La última intervención en la Puerta de Córdoba de Carmona

- Las gentes de Carmona a través de la Puerta

En este capítulo proponemos presentar la evolución de la Puerta desde su contrucción hasta hoy día, 
procurando transmitir qué es lo que cambia y por qué y cómo lo hace, y qué queda intacto, casi congelado en el tiempo, soportando el "peso" del edificio, siendo el esqueleto vertebrador que impide que los agentes naturales y antrópicos desvirtúen por completo el plan original. Así, y a pesar de los sacrificios materiales y espaciales y de los cambios de funcionalidad que experimenta, comprobamos cómo la Puerta mantiene intactos a lo largo de casi dos milenios sus valores fundamentales.

Si el Edificio nace con una doble funcionalidad, la defensiva y la propagandística, vemos cómo muy pronto, posiblemente a partir del siglo II y, sobre todo, en época tardorromana, el programa monumental comienza a verse ensombrecido debido a la necesidad de mejorar la inexpugnabilidad de la estructura. Esta tendencia se hace dominante en la etapa medieval y no es hasta el Renacimiento cuando, gracias a la estabilidad política del Reino, la Puerta empieza a ser recuperada de nuevo como emblema de la Ciudad. Las obras de finales del siglo XVIII proyectadas y dirigidas por Echamorro (figura que por su importancia en el contexto local y regional puede ser tratado de manera singular dentro de la temática) podrían ser fijadas quizá como la consolidación del resurgimiento que empieza a operarse casi trescientos años antes.

Aquí es obligado aludir al que es, sin duda, el problema de conservación más persistente, constatado ya en época Flavia, al que se refiere reiteradamente la documentación escrita estudiada: las patologías originadas por la propia ubicación del edificio en una vaguada entre dos escarpes del alcor (debidas a filtraciones y escorrentías desde los escarpes donde se inserta la Puerta y a la acción erosiva del regajo que discurre por el subsuelo, pendiente abajo). En este bloque cabría presentar, a nuestro entender, la última intervención operada en la Puerta de
Córdoba. La investigación llevada a cabo por el I.A.P.H. ha procurado toda suerte de detalles acerca no sólo de los componentes del bien inmueble, sino, también, de su conjugación para llegar a conformarlo. Piedra, ladrillo, arena, cal se yuxtaponen, se encastran, se funden, en uniones no siempre naturales, para situarnos ante un edificio donde se evidencia una unidad compositiva y cierta coherencia estética.

Creemos, así, que es temática de la interpretación el trabajo interdisciplinar llevado a cabo por la Consejería de Cultura ${ }^{5}$ para el estudio, valoración y restauración de la Puerta de Córdoba. Y esto no por otra razón sino porque el ciudadano que ha sufragado la empresa, que la ha encargado y que va a recibir el producto resultante, lo valorará de modo más completo si conoce también el proceso que se ha seguido para su recuperación. Si la comunicación se produce con eficacia, habremos puesto en marcha la mejor de las medidas de conservación: la "actitud de conservar", que tiene, además, carácter preventivo.

El tema centrado en las gentes de Carmona vuelve a situar el Edificio en su contexto local; es casi un recorrido antropológico, etnográfico, por los habitantes de Carmona y sus actividades, en especial por aquellos que a diario, desde tiempos que sólo existen ya en la memoria de los viejos, han atravesado el arco de la Puerta para desempeñar su labor, el pastoreo, la recolección, la compraventa, la herrería, la cantería, la caza. Y si al tratar estas actividades atendemos la faceta activa de la población, al hablar del turismo, del incesante fluir de los vehículos alquilados en los aeropuertos, estamos contemplando la pasiva, no menos interesante, puesto que es también agente modelador de la comunidad que es visitada. En este capítulo, en suma, es la Puerta la que rinde homenaje a los carmonenses, a los que ya no están y a los que ahora la contemplan renovada.

\section{Notas}

I. Nos hemos ocupado, hasta la fecha, de trasladar el fruto de los trabajos realizados en la Puerta a la comunidad científica y a los profesionales del Patrimonio Histórico en general, tarea que culminará pronto con la presentación de una monografía.

2. Entre ambos modos museográficos, entre ambos lugares expositivos, existe, además, un espacio tangente a la que es, aún hoy día, una importante vía de comunicación tanto de la ciudad en sí misma como de ésta con el mundo extramuros. Podría tratarse este trayecto como elemento de adaptación de uno a otro extremo, de una a otra manera de presentación. Esto permitiría, con la inclusión de escasos y escogidos materiales comunicativos, incorporar al recorrido otros bienes o productos patrimoniales que ayuden a contextualizar el mensaje y a evidenciar la unión indisoluble entre la Ciudad y la Puerta.

3. El Centro de Intervención del I.A.P.H. está ultimando una propuesta de restitución de la Puerta del siglo I d.C.

4. Bellum Civile II, 19, 4.

5. Con la colaboración del Ayuntamiento de Carmona. 